\title{
Oral anticoagulation with rivaroxaban as thromboprophylaxis in patients recovered from COVID- 19 pneumonia in Veracruz, Mexico
}

\begin{abstract}
Background: Patients affected by COVID-19 are at risk of various venous and arterial thrombotic events, as well as embolic risks, the risk can vary from $17 \%$ to $78 \%$ according to the different published series. Therefore, thromboprophylaxis must be imperative.

Methods: Descriptive and analytical study in patients who presented pneumonia due to COVID-19 in April and May 2020, who received LMWH during their hospital stay and at discharge with rivaroxaban $10 \mathrm{mg} /$ day for 2 months. D-dimer was measured at the beginning of the study and 1 month after discharge. Thrombotic or hemorrhagic episodes are controlled after 1 and 2 months of treatment (June - July 2020).

Results: 50 patients are included, twenty women $(40 \%)$ and thirty $(60 \%)$ men, with a median age of 42.9 years. $32(64 \%)$ patients had mild pneumonia and $18(36 \%)$ patients had severe pneumonia, mean initial d-dimer $556.5(375.2$ - 1233.7) $\mathrm{ng} / \mathrm{ml}, 56 \%$ of patients had d-dimer $\geq 500 \mathrm{ng} / \mathrm{ml}$ at the time of hospital admission. Baseline D-dimer values were significantly higher among patients with severe pneumonia. In the follow-up at one and two months after hospital discharge, we found that D-dimer values were significantly higher among patients with severe pneumonia and also, in this group of patients, the percentage of patients with D-dimer levels $\geq 500 \mathrm{ng} / \mathrm{mL}$ in the first month of follow-up, was significantly higher in the group of patients who were hospitalized for severe pneumonia. During the first month of follow-up, there was a thrombotic event and a hemorrhagic event in the group of patients with a history of severe pneumonia; by the second month of follow-up, there was a hemorrhagic event in the group of patients with mild pneumonia, but this difference in frequencies was not statistically significant.
\end{abstract}

Conclusion: In this group of patients, the incidence of thrombotic and hemorrhagic events was low, so the thromboprophylaxis scheme used in patients with recovered pneumonia due to COVID-19 is recommended. Rivaroxaban is safe to use like thromboprophylaxis.

Keywords: rivaroxaban, thromboprophylaxis, COVID-19

\author{
Volume I3 Issue I - 202 I
}

Luis Del Carpio-Orantes,' Sergio GarcíaMendez, ${ }^{2}$ Jesús Salvador Sánchez-Díaz, ${ }^{3}$ Karla Gabriela Peniche-Moguel, ${ }^{3}$ Elisa Estefanía Aparicio-Sánchez,' Orlando Israel Segura-Rodríguez,' Andrés AguilarSilva,' Omar García-Hernández,' Alejandro Escobar-Huerta,' Azael Ahumada-Zamudio,' Andrés Realino Velasco-Caicero,' Olga González-Segovia,' Ernesto Javier PachecoPérez,' Álvaro Efrén Munguia-Sereno,' Edna Rosario Contreras-Sánchez,' Sara Nohemí Hernández-Hernández,' Luis Jaime Medrano-Rios, ' Ada Lili Rosas-Lozano ${ }^{4}$

'Department of Internal Medicine, General Hospital 7I, North Veracruz Delegation, Instituto Mexicano del Seguro Social, Mexico

${ }^{2} \mathrm{Head}$ of Teaching and Research, Regional Hospital of High Specialty of Oaxaca, Mexico

${ }^{3}$ Critical Care Unit, High Specialty Medical Unit 189, North Veracruz Delegation, Instituto Mexicano del Seguro Social, Mexico

${ }^{4}$ Department of Hematology, High Specialty Medical Unit I89, North Veracruz Delegation, Instituto Mexicano del Seguro Social, Mexico

\author{
Correspondence: Luis Del Carpio Orantes, Department \\ of Internal Medicine, General Hospital 7I, North Veracruz \\ Delegation, Instituto Mexicano del Seguro Social, Díaz Mirón \\ S/N, Floresta,Veracruz, México, Tel 2292237032, \\ Email Neurona23@hotmail.com
}

Received: January 18, 2021 | Published: February 04, 2021

\section{Introduction}

The first descriptions of pneumonia associated with Sars Cov 2 associated it with severe hypoxemic acute respiratory failure, coupled with hyperinflammation that can lead to multiple organ failure, however, with the evolution of the case study, the participation of microvascular thrombosis was observed which added comorbidity and high mortality in these pictures, currently being considered a picture of thromboinflammation. ${ }^{1,2}$ Clinically, it is expressed as hypoxemic pneumonia and initial coagulopathy with a high expression of D-dimer and fibrinogen degradation products, with abnormal clotting times and platelets being rare. The determination of elevated D-dimer (with a cut-off of $6.494 \mathrm{ng} / \mathrm{ml}$ in a Chinese study of 158 patients) is considered a risk factor for developing deep vein thrombosis associated with COVID-19 and this has been established as having a high prevalence in this virus. ${ }^{3-5}$ An Italian study studied venous thromboembolism, which includes deep vein thrombosis and its main complication, pulmonary embolism, which appears to occur with a higher incidence in seriously ill patients who require intensive care. This study revealed the presence of asymptomatic deep vein thrombosis and independent pulmonary embolism in patients with COVID-19. ${ }^{6}$

A Dutch study demonstrated venous thromboembolism in patients admitted to intensive care in $27 \%$ of 184 patients, of these $81 \%$ presented pulmonary embolism; also identified arterial thrombotic events in 3.7\%. ${ }^{7}$ Other thrombotic manifestations include acute cerebrovascular disease (mainly ischemic) which was more common among 88 patients with severe COVID-19 than among those with nonsevere disease $(5.7 \%$ vs. $0.8 \%)$. Another study mentions that $1.5 \%$ of patients admitted to the emergency room or hospitalization present acute cerebral ischemia. A Chinese study of 1,875 cases reported 50 cases of acute cerebrovascular disease $(90 \%$ ischemic and $10 \%$ hemorrhagic) ${ }^{8-11}$ An American study in 3,556 patients diagnosed with COVID-19 reported that $0.9 \%$ had an acute stroke, of these $43.8 \%$ had a neurological deficit upon admission to the emergency room, and $56.2 \%$ developed the deficit during their hospital stay. ${ }^{12}$

Similarly, in patients with COVID-19, the presence of acute cardiac injury, shock and arrhythmias has been reported in $7.2 \%$, 
$8.7 \%$ and $16.7 \%$ respectively, which may favor thrombotic coronary artery disease and embolism of cardiac origin. ${ }^{13}$

Given the above, the current concern is the management of prophylactic or therapeutic anticoagulation, there are recommendations for the use of LMWH during acute events and oral anticoagulants gaining ground in the convalescence phase, which incidentally is also considered to be of high thrombotic risk -embolic due to the long hospital stay, immobility of the patient, the presence of asymptomatic peripheral venous thrombosis and the high incidence of chronic degenerative diseases considered prothrombotic that are associated.

At the patient's discharge, it is recommended to maintain anticoagulation for at least 45 to 60 days due to post-COVID-19 thrombotic risks, preferring oral anticoagulants such as rivaroxaban, because they do not need monitoring, they can be administered in daily single doses and facilitate the discharge plan and management ambulatory. ${ }^{14-16}$

\section{Material and methods}

A descriptive and analytical study is carried out in patients who presented pneumonia due to COVID-19 in April and May 2020 at the General Hospital 71 of the Veracruz North delegation of the Mexican Institute of Social Security, monitoring them for two months after discharge hospitable. Confirmation of pneumonia due to COVID-19 was by RT-PCR as well as by pulmonary axial tomography; a baseline D-dimer measurement was taken in the first 5 days of hospital admission, as well as a D-dimer control in the first month of

Table I Results of the measurement of demographic and clinical variables of patients with COVID-I9 who were discharged with anticoagulant treatment* discharge, taking values greater than $500 \mathrm{ng} / \mathrm{mL}$ as high thrombotic risk. All received low molecular weight heparin (enoxaparin) during their hospital stay at a dose of $1 \mathrm{mg} / \mathrm{kg} /$ day, starting with rivaroxaban in a single dose of $10 \mathrm{mg} /$ day that was administered for 2 months.

\section{Results}

We analyzed the data of 50 patients who had a hospital stay with a confirmed diagnosis of COVID-19 pneumonia by RT-PCR, twenty women $(40 \%)$ and thirty $(60 \%)$ men, with a median age of 42.9 (IQR 32.7 - 61.7) years. The most frequent comorbidity was diabetes mellitus in $25(50 \%)$ patients, followed by systemic arterial hypertension with $15(30 \%)$ patients, $3(6.0 \%)$ patients with peripheral vascular insufficiency and $1(2.0 \%)$ patient with a history of arrhythmia without anticoagulant treatment.

The results of the measurement of laboratory parameters are found in Table 1, which highlights the baseline median d-dimer [556.5 (375.2 - 1,233.7) ng/mL], 56\% of the patients had d-dimer $\geq 500 \mathrm{ng} / \mathrm{mL}$ at the time of hospital admission. Regarding the type of pneumonia, we found that $32(64 \%)$ patients had mild pneumonia and $18(36 \%)$ patients had severe pneumonia; with a median of 7.0 (5.0 - 15.0) days of hospital stay. At one-month follow-up, $28(56 \%)$ patients remained with d-dimer levels $\geq 500 \mathrm{ng} / \mathrm{mL}$. During the first month one patient had an ischemic stroke and one patient had upper gastrointestinal bleeding. For the second month of follow-up, there was one patient who presented self-limited epistaxis. Measurement of demographic and clinical variables of patients with a confirmed diagnosis of COVID-19 stratified by type of pneumonia.

\begin{tabular}{|c|c|}
\hline Variable & $\begin{array}{l}\text { Result } \\
n=50\end{array}$ \\
\hline \multicolumn{2}{|l|}{ Demographic variables } \\
\hline \multicolumn{2}{|l|}{ Gender } \\
\hline Woman & $20(40.0)$ \\
\hline Man & $30(60.0)$ \\
\hline Age; years, median (IQR) & $42.0(32.7-61.7)$ \\
\hline \multicolumn{2}{|l|}{ Previous comorbidities } \\
\hline Diabetes mellitus & $25(50.0)$ \\
\hline Systemic hypertension & $15(30.0)$ \\
\hline Vascular insufficiency & $3(6.0)$ \\
\hline Arrhythmia & I (2.0) \\
\hline \multicolumn{2}{|l|}{ Variables associated with COVID-19 } \\
\hline Leukocytes; cells / mm³, median (IQR) & $9,800.0(7097.5-11,850.0)$ \\
\hline Neutrophils; cells / mm³ , median (IQR) & $7,850.0(5,275.0-10,527.5)$ \\
\hline Lymphocytes; cells / mm³ , median (IQR) & I, I $05.0(865.0-1,527.5)$ \\
\hline Platelets; cells / mm³ , median (IQR) & $198,000.0(167,750.0-327,000.0)$ \\
\hline Basal D-dimer; ng / mL, median (IQR) & $556.5(375.2-1,233.7)$ \\
\hline Baseline D-dimer $\geq 500 \mathrm{ng} / \mathrm{mL}$ & $28(56.0)$ \\
\hline \multicolumn{2}{|l|}{ Type of pneumonia } \\
\hline Mild pneumonia & $32(64.0)$ \\
\hline Severe pneumonia & $18(36.0)$ \\
\hline Days of hospital stay; median (IQR) & $7.0(5.0-15.0)$ \\
\hline
\end{tabular}

Citation: Carpio-Orantes LD, García-Mendez S, Sánchez-Díaz JS, et al. Oral anticoagulation with rivaroxaban as thromboprophylaxis in patients recovered from COVID-19 pneumonia in Veracruz, Mexico. J Anesth Crit Care Open Access. 202 I; I3(I): I 2-1 5. DOI: 10. I5406/jaccoa.202 I. I 3.00463 


\begin{tabular}{|c|c|}
\hline Variable & $\begin{array}{l}\text { Result } \\
\mathbf{n}=\mathbf{5 0}\end{array}$ \\
\hline \multicolumn{2}{|c|}{$\begin{array}{l}\text { Measurement of d-dimer at the first month of follow-up, and of thrombotic and } \\
\text { hemorrhagic events at one and two months of follow-up. }\end{array}$} \\
\hline D-dimer at the first month; $\mathrm{ng} / \mathrm{mL}$, median (IQR) & $454.0(377.2-705.0)$ \\
\hline D-dimer $\geq 500 \mathrm{ng} / \mathrm{mL}$ at first month & $28(56.0)$ \\
\hline Thrombotic events during the first month & I (2.0) \\
\hline Bleeding events during the first month & I (2.0) \\
\hline Thrombotic events during the second month & $0(0.0)$ \\
\hline Bleeding events during the second month & I (2.0) \\
\hline
\end{tabular}

*Results expressed with $\mathrm{n}$ and \%, except when otherwise indicated

We performed a comparative analysis of the demographic and clinical variables stratified by the type of pneumonia that they presented during the hospital stay (Table 2); we found that in terms of gender there were no differences regarding the frequency of presentation of mild or severe pneumonia. However, the median age was lower in the group of patients with mild pneumonia compared to the median age of patients with severe pneumonia [35.5 (32.0 - 48.7) VS 56.6 (41.7
- 73.5) years, respectively) and that this difference was statistically significant $(\mathrm{p}=0.001)$. Regarding comorbidities, we found that only diabetes mellitus was significantly more frequent among patients with severe pneumonia (72.2 VS $37.5 \%$; $=0.038$ ). With regard to systemic arterial hypertension, vascular insufficiency, and a history of arrhythmia, there was a tendency to be more frequent in the group of patients with severe pneumonia, but it was not statistically significant.

Table 2 Results of the measurement of demographic and clinical variables of patients with a confirmed diagnosis of COVID-I9 who were discharged with anticoagulant treatment stratified by type of pneumonia*

\begin{tabular}{|c|c|c|c|}
\hline Variable & $\begin{array}{l}\text { Mild pneumonía } \\
\mathrm{n}=32\end{array}$ & $\begin{array}{l}\text { Severe pneumonía } \\
n=18\end{array}$ & $\mathbf{p}$ \\
\hline \multicolumn{4}{|l|}{ Demographic variables } \\
\hline \multicolumn{4}{|l|}{ Gender } \\
\hline Woman & $13(40.6)$ & 7 (38.9) & $1.000^{\S}$ \\
\hline Man & $19(59.4)$ & II (6I.I) & $1.000^{\S}$ \\
\hline Age; years, median (IQR) & $35.5(32.0-48.7)$ & $56.6(4 I .7-73.5)$ & $0.00 I^{Y}$ \\
\hline \multicolumn{4}{|l|}{ Previous comorbidities } \\
\hline Diabetes mellitus & $12(37.5)$ & $13(72.2)$ & $0.038^{\S}$ \\
\hline Systemic hypertension & $7(21.9)$ & $8(44.4)$ & $0.117 \S$ \\
\hline Vascular insufficiency & I (3.I) & $2(I I . I)$ & $\left.0.29\right|^{\S}$ \\
\hline Arrhythmia & $0(0.0)$ & I (5.6) & $0.360^{\S}$ \\
\hline \multicolumn{4}{|l|}{ Variables associated with COVID-19 } \\
\hline Leukocytes; cells / mm³ median (IQR) & $9,800.0(7,275.0-11,225.0)$ & $9,400.0(6,667.5-12,600.0)$ & $\left.0.53\right|^{Y}$ \\
\hline Neutrophils; cells / mm³, median (IQR) & $7,505.0(5,225.0-8,740.0)$ & $7,990.0(5,250.0-11,000.0)$ & $0.342^{Y}$ \\
\hline Lymphocytes; cells / mm³, median (IQR) & $\mathrm{I}, 225.0(\mathrm{I}, 020.7-\mathrm{I}, 6 \mathrm{I} 7.5)$ & $925.0(645.0-1,210.0)$ & $0.005^{Y}$ \\
\hline Platelets; cells / mm³ , median (IQR) & $203,000.0(169,750.0-345,750.0)$ & $|8|, 000.0(\mid 66,000.0-268,500.0)$ & $0.322^{Y}$ \\
\hline Basal D-dimer; ng / mL, median (IQR) & $410.0(341.7-556.7)$ & $\mid, 880.0(|| 75.0-3,, \mid 87.0)$ & $0.00 I^{Y}$ \\
\hline Baseline D-dimer $\geq 500 \mathrm{ng} / \mathrm{mL}$ & II (34.4) & $17(94.4)$ & $0.00 I^{\S}$ \\
\hline Days of hospital stay; median (IQR) & $7.0(5.0-7.0)$ & $17.0(\mid 4.0-20.2)$ & $0.00 I^{Y}$ \\
\hline \multicolumn{4}{|c|}{ Measurement of d-dimer at the first month of follow-up, and of thrombotic and hemorrhagic events at I and 2 months of follow-up. } \\
\hline D-dimer at the first month; $\mathrm{ng} / \mathrm{mL}$, median (IQR) & $390.0(349.2-463.2)$ & $835.0(655.0-1,125.0)$ & $0.00 I^{Y}$ \\
\hline D-dimer $\geq 500 \mathrm{ng} / \mathrm{mL}$ at first month & $2(6.3)$ & $16(88.9)$ & $0.00 I^{\S}$ \\
\hline Thrombotic events during the first month & $0(1.0)$ & I (5.6) & $0.360^{\S}$ \\
\hline Bleeding events during the first month & $0(0.0)$ & I (5.6) & $0.360^{\S}$ \\
\hline Thrombotic events during the second month & $0(0.0)$ & $0(0.0)$ & $1.000^{\S}$ \\
\hline Bleeding events during the second month & I (3.I) & $0(0.0)$ & $1.000 \S$ \\
\hline
\end{tabular}

*Results expressed with $\mathrm{n}$ and \%, except when otherwise specified. §Chi square. $\mathrm{Y} U$ of Mann-Whitney

Citation: Carpio-Orantes LD, García-Mendez S, Sánchez-Díaz JS, et al. Oral anticoagulation with rivaroxaban as thromboprophylaxis in patients recovered from COVID-19 pneumonia in Veracruz, Mexico. J Anesth Crit Care Open Access. 202 I; I3(I): I 2-I 5. DOI: 10.15406/jaccoa.202 I.13.00463 
Regarding the variables associated with COVID-19, we found the values of lymphocytes [925.0 (645.0 1,210.0) VS 1,225.0 (1,020.7 - 1,617.5) lymphocytes; $p=0.005]$ were significantly lower in the group of patients with severe pneumonia. The white blood cell and platelet values tended to be lower in the group of patients with severe pneumonia, but this difference was not statistically significant. Baseline dimer values were significantly higher among patients with severe pneumonia $[1,880.0(1,175.0$ - 3,187.0) VS 410.0 (341.7 - 556.7) $\mathrm{ng} / \mathrm{mL} ; \mathrm{p}=0.001]$; in addition, the percentage of patients with baseline d-dimer $\geq 500 \mathrm{ng} / \mathrm{mL}$ with severe pneumonia (94.4 VS $34.4 \% ; \mathrm{p}=0.001)$ and hospital stay [17.0 (14.0 - 20.2) VS 7.0 (5.0 $7.0) ; \mathrm{p}=0.001]$, were also significantly higher among patients with severe pneumonia.

In the follow-up at one and two months after hospital discharge, we found that D-dimer values were significantly higher among patients who had severe pneumonia [835.0 (655.0 - 1,125.0) VS 390.0 (349.2 - 463.2); $\mathrm{p}=0.001]$; Additionally, in this group of patients, the percentage of patients with d-dimer levels $\geq 500 \mathrm{ng} / \mathrm{mL}$ at the first month of follow-up was significantly higher in the group of patients who were hospitalized with severe pneumonia ( 88.9 vs. $6.3 \%$; $p=$ 0.001). During the first month of follow-up, there was a thrombotic event and a hemorrhagic event in the group of patients with a history of severe pneumonia; for the second month of follow-up, there was a hemorrhagic event in the group of patients who had mild pneumonia, but this difference in frequencies was not statistically significant.

\section{Conclusion}

In this group of patients, the incidence of thrombotic events associated with COVID-19 is low compared to that reported in the world literature, probably favored by the anticoagulation strategy applied with LMWH in the acute stage and rivaroxaban in the convalescent stage, and In the presence of overt prothrombotic (diabetes, hypertension) and thrombotic risk factors (pneumonia and elevated baseline D-dimer and persistently elevated in the convalescent phase), the incidence of bleeding events is low and with self-limited events. More studies based on this regimen are needed to give further weight to the recommendation.

\section{Conflicts of interest}

The authors declare there are no conflicts of interest.

\section{References}

1. Del Carpio-Orantes L. Del 2019-nCoV al COVID-19, caracterizando la enfermedad. Med Int Méx. 2020;36(3):414-417.

2. Gris JC, Perez-Martin A, Quéré I, Sotto A. COVID-19 associated coagulopathy: The crowning glory of thrombo-inflammation concept. Anaesth Crit Care Pain Med. 2020;39(3):381-382.
3. Connors JM, Levy JH. COVID-19 and its implications for thrombosis and anticoagulation. Blood. 2020;135(23):2033-2040.

4. Koleilat I, Galen B, Choinski K, et al. Clinical characteristics of acute lower extremity deep venous thrombosis diagnosed by duplex in patients hospitalized for coronavirus disease 2019 [published online ahead of print, 2020 Jun 25]. J Vasc Surg Venous Lymphat Disord. 2020;S2213-333X(20)30348-6.

5. Cho ES, McClelland PH, Cheng O, et al. Utility of D-dimer for diagnosis of deep vein thrombosis in COVID-19 infection [published online ahead of print, 2020 Jul 29]. J Vasc Surg Venous Lymphat Disord. 2020;S2213-333X(20)30420-0.

6. Cattaneo M, Bertinato EM, Birocchi S, et al. Pulmonary Embolism or Pulmonary Thrombosis in COVID-19? Is the Recommendation to Use High-Dose Heparin for Thromboprophylaxis Justified?. Thromb Haemost. 2020;120(8):1230-1232.

7. Klok FA, Kruip MJHA, van der Meer NJM, et al. Incidence of thrombotic complications in critically ill ICU patients with COVID-19. Thromb Res. 2020;191:145-147.

8. Zhang L, Feng X, Zhang D, et al. Deep Vein Thrombosis in Hospitalized Patients with COVID-19 in Wuhan, China: Prevalence, Risk Factors, and Outcome [published correction appears in Circulation. Circulation. 2020;142(2):114-128.

9. Mao L, Jin H, Wang M, et al. Manifestaciones neurológicas de pacientes hospitalizados con enfermedad por coronavirus 2019 en Wuhan, China. JAMA Neurol. 2020

10. Merkler AE, Parikh NS, Mir S, et al. Risk of Ischemic Stroke in Patients with Covid-19 versus Patients with Influenza. Preprint. medRxiv. 2020;2020.05.18.20105494.

11. Qin C, Zhou L, Hu Z, et al. Características clínicas y resultados de los pacientes con COVID-19 con antecedentes de accidente cerebrovascular en Wuhan, China. Carrera. 2020;51.

12. Yaghi $\mathrm{S}$, Ishida $\mathrm{K}$, Torres $\mathrm{J}$, et al. SARS2-CoV-2 y accidente cerebrovascular en un sistema de salud de Nueva York. Carrera. 2020; 51

13. Wang D, Hu B, Hu C, et al. Características clínicas de 138 pacientes hospitalizados con neumonía infectada por el nuevo coronavirus de 2019 en wuhan, China. JAMA. 2020.

14. Paranjpe I, Fuster V, Lala A, et al. Association of treatment dose anticoagulation with in-hospital survival among hospitalized patients with COVID-19. J Am College Cardiol. 2020.

15. Bikdeli B, Madhavan MV, Jimenez D, et al. COVID-19 and thrombotic or thromboembolic disease: implications for prevention, antithrombotic therapy, and follow-up. J Am Coll Cardiol. 2020.

16. Del Carpio-Orantes L, González-Segovia O, Mojica-Ríos F, et al. Neumonía grave por COVID-19 curada con prono consciente y tocilizumab. Comunicación de un caso y revisión de la evidencia terapéutica farmacológica. Med Int Méx. 2020;36(4):585-595. 